\title{
Spatial-Temporal Evolution of Drought Characteristics Over Hungary Between 1961 and 2010
}

\author{
K. Alsafadi, ${ }^{1}$ (D) S. A. Mohammed, ${ }^{2}$ (D)
}

Abstract-Historically, Hungary has witnessed numerous waves of drought episodes, causing significant agro-economic loss. Over the recent decades, the intensity, severity and frequency of drought occurrence have dramatically shifted, with undisputable upward tendencies across many areas. Thus, the main aim of this study was to characterize drought trends, intensity and duration over Hungary during 1961-2010. To attain the study goals, the present analyses utilized climate datasets obtained from Climate of the Carpathian region project-CARPATCLIM for 1045 gridded points covering entire Hungary. Meanwhile, a well-known drought index, namely; standardized precipitation index (SPI) and the standardized precipitation evapotranspiration index (SPEI) at 12-month timescales were employed for drought characterization. Furthermore, the sub-set regions of drought in Hungary were identified using S-mode of the principal component analysis. The Mann-Kendall trend test analysis showed a significant negative SPI-12 trend $(\mathrm{P}<0.05)$ in $11.5 \%$ of the total points over the western part of Hungary. In comparison, $43.2 \%$ of the total numbers of the SPEI-12 time series gridded points showed a significant negative trend $(\mathrm{P}<0.05)$ over the similar locale. However, both indices' trends highlighted the fact that the northeastern region is less sensitive to drought despite experiencing the highest of total drought duration. Results also suggested that the SPI-12 indicates that no significant change can be detected from 1961 to 2010 over Hungary. In contrast, the SPEI-12 exhibits that the drought waves that hit Hungary were more pronounced, with a significant positive $(\mathrm{P}<0.05)$ trend of $+1.4 \%$ per decade being detected for the area affected by very extreme drought. All in all, this study is one of the primary steps toward a better understanding of drought vulnerability assessment in Hungary.

K. Alsafadi and S. A. Mohammed contributed equally to this work.

1 Department of Geography and GIS, Faculty of Arts, Alexandria University, Alexandria 25435, Egypt.

2 Institution of Land Utilization, Technology and Regional Planning, Faculty of Agricultural and Food Sciences and Environmental Management, University of Debrecen, Debrecen 4032, Hungary. E-mail: safwan@agr.unideb.hu

3 Key Laboratory of Meteorological Disaster, Ministry of Education (KLME)/Joint International Research Laboratory of Climate and Environment Change (ILCEC)/Collaborative Innovation Center on Forecast and Evaluation of Meteorological Disasters (CIC-FEMD), University of Information Science and Technology, Nanjing 210044, China.

\author{
B. Ayugi, ${ }^{3}$ M. Sharaf, ${ }^{1}$ and E. HarsányI ${ }^{2}$
}

Keywords: SPI-12, SPEI-12, hydrological drought, drought hazard, Hungary, Central Europe.

$\begin{array}{ll}\text { Abbreviations } \\ \text { EOF } & \text { Empirical orthogonal function } \\ \text { M-K } & \text { Mann-Kendall } \\ \text { PaDI } & \text { Palfai drought index } \\ \text { PCA } & \text { Principal component analysis } \\ \text { PDSI } & \text { Palmer drought severity index } \\ \text { PET } & \text { Potential evapotranspiration } \\ \text { SEoD } & \text { Spatial extent of drought } \\ \text { SPEI } & \text { Standardized precipitation } \\ & \text { evapotranspiration index } \\ \text { SPI } & \text { Standardized precipitation index } \\ \text { TDD } & \text { Total drought duration }\end{array}$

\section{Introduction}

Recently, European countries have been warming rapidly in comparison with many other parts of the world (Hernández-Morcillo et al. 2018). Moreover, the European Environmental Agency EEA (2017) indicated that the average temperature from 2006 to 2015 increased by $1.5^{\circ} \mathrm{C}$, warmer than the pre-industrial level, while heat-waves increased in frequency and length. On the other hand, precipitation has recorded a significant decline in recent times in the southern parts of Europe (Vicente-Serrano et al. 2014), while the intensity and frequency of rainstorms in the northern parts of the continent have increased. Interestingly, drought episodes have become more vigorous and longer, associated with increased temperature and low rainfall, especially in the center of the Europe (i.e. Hungary) (Bussay and 
Szinell 1996; Bartholy et al. 2013; Kern et al. 2016). Historically, drought episodes have hit Europe many times, causing major damage in the economic and agricultural sectors (Vicente-Serrano et al. 2014), with the yearly impact reaching 5.3 billion $€$ in Europe since 1991 (Feyen and Dankers 2009). Interestingly, the European Environment Agency reported that over the past 30 years $17 \%$ of the European Union's lands area has been were affected by water scarcity, resulting in losses of 100 billion $€$ (EEA 2009).

Hungary is one of the European countries located in the Carpathian region affected by drought episodes and climate change, as are other countries (Gálos et al. 2007). In the last few decades, specifically since the 1980s, drought has become a recurrent feature of Hungary's climate, and it seems the drought trends will extend towards the end of the 21 st century (Gálos et al. 2007).

Bartholy et al. (2013) predicted a significant change in the future rainfall patterns of Hungary (i.e. 2070-2100) with the summer becoming drier. Similarly, Blanka et al. (2013) highlighted the positive future trend of drought in Hungary where the Great Hungarian Plain will be subjected to an increase in the drought hazard by the end of the 21 st century which will gravely affect the agricultural system. In a similar vein, Sábitz et al. (2014) emphasized the remarkable drought trends in the Carpathian region, where the necessary steps toward drought mitigation should be taken. Interestingly, Kertész (2016) argued that Hungary is more susceptible to desertification due to different factors such as decreasing precipitation and increasing temperature associated with extreme events, as a direct result of climate change. Historically, between 1983 and 1995 drought episodes over Hungary were responsible for $36 \%$ of all agricultural losses (Szinell et al. 1998; Szalai et al. 2000). Moreover, the drought of 2003 caused more than 55 billion HUF of economic damage, with the temperature breaking the previous record and reaching $45{ }^{\circ} \mathrm{C}$ in the national average (Puskás et al. 2012). Fiala et al. (2014) reported a significant yield loss of between 40 and 50\% in the southern Great Plain of Hungary, due to drought and heatwaves.

In order to detect and characterize drought, more than 100 drought indices have so far been developed
(Zargar et al. 2011), including the standardized precipitation evapotranspiration index (SPEI) (VicenteSerrano et al. 2010), the standardized precipitation index (SPI) (McKee et al. 1993), the Palfai Drought Index (PaDI) (Pálfai and Herceg 2011), the Palmer drought severity index (PDSI) (Palmer 1965) and many others. Among them the SPI and the SPEI has been widely used all over the world (e.g. Italy (Caloiero and Veltri 2019); India (Kumar et al. 2019); Portugal (Raziei et al. 2015); Syria (Mathbout et al. 2018); Syria (Mohammed et al. 2019); Slovakia (Labudová et al. 2017; Vido et al. 2019); Kenya (Ayugi et al. 2020); Serbia (Bezdan et al. 2019); the USA (Hernandez and Uddameri 2014) and China (Wang et al. 2016; Fang et al. 2018; Jin et al. 2019) for analyzing different types of drought, including meteorological, agricultural, hydrological and socioeconomic drought.

In recent decades, many studies have been conducted to investigate drought trends and their relation to other variables in Hungary (e.g. Szabó et al. 2018; Kern et al. 2016; Mika et al. 2005; Horvath et al. 2005). To the best of our knowledge, none of them have applied the SPI nor the SPEI methods as a main indicator of drought. Therefore, this study is the first of its kind to provide a spatially explicit study of drought characterization in Hungary, with special emphasis on drought on the sub-regional scale as a basis for any future climate change adaptation and resilience plans. All in all, the main objectives of this research were to: (1) identify regions in Hungary with the same temporal variability of drought, by using the SPI-12 and the SPEI-12 for 1045 gridded points covering the majority of Hungary; (2) identify regions exposed to drought, and (3) highlight area that was most susceptible to drought in Hungary between 1961 and 2010, by examining the temporal evolution of area affected by different drought categories. The remaining section of this study is organized as follows: Sect. 2 elaborates the description of the study domain, data and methods employed while Sect. 3 explicitly presents the results and discussions, respectively. Finally, Sect. 4 gives conclusion and possible recommendation for future study. 


\section{Methods}

\subsection{Study Area and Data Collection}

Hungary is located in the center of Europe between latitudes $45^{\circ} 55^{\prime} \mathrm{N}-48^{\circ} 60^{\prime} \mathrm{N}$ and longitudes $16^{\circ} 10^{\prime} \mathrm{E}-22^{\circ} 50^{\prime} \mathrm{E}$, covering an area of $93,000 \mathrm{~km}^{2}$. The climate is characterized as a continental climate, in which winters (December, January, February) are cold and snowy, and summers (June, July, August) are hot and dry (Hungarian metrological service: https:// www.met.hu/en/idojaras/). Generally, the climate of Hungary is influenced by its location in the Carpathian Basin, and can be characterized as a continental climate, meaning warm and dry summers, and cold and wet winters (Ács et al. 2015; Breuer et al. 2017). According to Szabó et al. (2018), rainfall can occur due to three factors (1) the Mediterranean factor in the eastern part, (2) the oceanic factor in the western part, and (3) continental factors in the Great Hungarian Plain; thus, any changes in the world climate will have an effect on precipitation patterns in Hungary.

The landscape can be divided into plains (the Kisalföld and the Great Hungarian Plain), hills (the Transdanubian Hills) and mountains (the Transdanubian Mountains, The Northern Hungarian Mountains and the Alpine foothills (Alpokalja, omitted from this study due to lack of data) (Szabó et al. 2018).

The rainfall data (monthly and yearly) from 1961 to 2010 as well as the SPI-12 and SPEI-12 time series were collected from the Climate of the Carpathian region project-CARPATCLIM (CARPATCLIM 2019). The project was financed by the European Commission (Szalai and Vogt 2011) and developed by a several institutions from nine countries in the Carpathian region, jointly with the European Commission's Joint Research Center (JRC). The final output of the project was the climate atlas of the region (Szalai et al. 2013). Data of 1045 gridded points covering the majority of the country was used, as can be seen in Fig. 1. This gridded database at spatial resolution: $0.1^{\circ} \times 0.1^{\circ}$ grid $(10 \mathrm{~km} \times 10 \mathrm{~km})$ interpolated from dataset of meteorological stations. The grids represent the SPI/SPEI computed over a twelve-month period values across the study area in the form of two-dimensional array. The data were obtained without checking their homogeneity, since the homogeneity and quality were ensured by the CARPATCLIM team (2012) (i.e. Bihari and Szentimrey 2013; Spinoni et al. 2015).

\subsection{Drought Indicators: the SPI and SPEI}

Although, precipitation is a critical indicator of the availability of water, but also both of precipitation and temperature together have an important role that influence in availability and stability of water. Therefore, they effect on the urban, agricultural, and ecosystems water supply, as well as, on agricultural production and forest stress, by control in the ratio of actual and potential evapotranspiration (Zhang et al. 2019; Chang et al. 2018; Novick et al. 2016; Williams et al. 2013). A several parameters such as rainfall, temperature, soil moisture, streamflow, river discharge, vegetation condition, and ecosystem responses can be used as indicators of drought (Vicente-Serrano et al. 2010; Narasimhan and Srinivasan 2005; Nalbantis and Tsakiris 2009; Sohrabi et al. 2015; Jiao et al. 2016; Anyamba and Tucker 2012; Chang et al. 2018). These indicators are transformed to drought indices at multiscale, which reflect the different characteristics of the drought (Vicente-Serrano et al. 2010). In this research we used both the SPI and the SPEI for drought monitoring over Hungary (Vicente-Serrano et al. 2010; McKee et al. 1993). The SPI is based only on monthly rainfall data; so, geographical and topographical differences are not considered (Mathbout et al. 2018). Meanwhile, SPEI is a newly improved index developed from the same background as SPI but based on rainfall and potential evapotranspiration (PET) (i.e. the monthly climatic water balance) (Vicente-Serrano et al. 2010; Wang et al. 2015; Tan et al. 2015). However, both of them are statistical indices and can be calculated for any time scale (i.e. for 1-, 3-, 6-, 9-, or 12-month time scales). The choice of the time scale is, in practice, dependent on the goal of the study. If it is related to agriculture drought then a 1-, 3-, or 6-month scale should be chosen, while a 9-, or 12-month scale is used for monitoring hydrological drought (Tan et al. 2015). In our study we used a SPI-12 and SPEI-12-time scale for detecting droughts over a long-term interval. SPI and SPEI values for drought can be classified, as can be seen in 


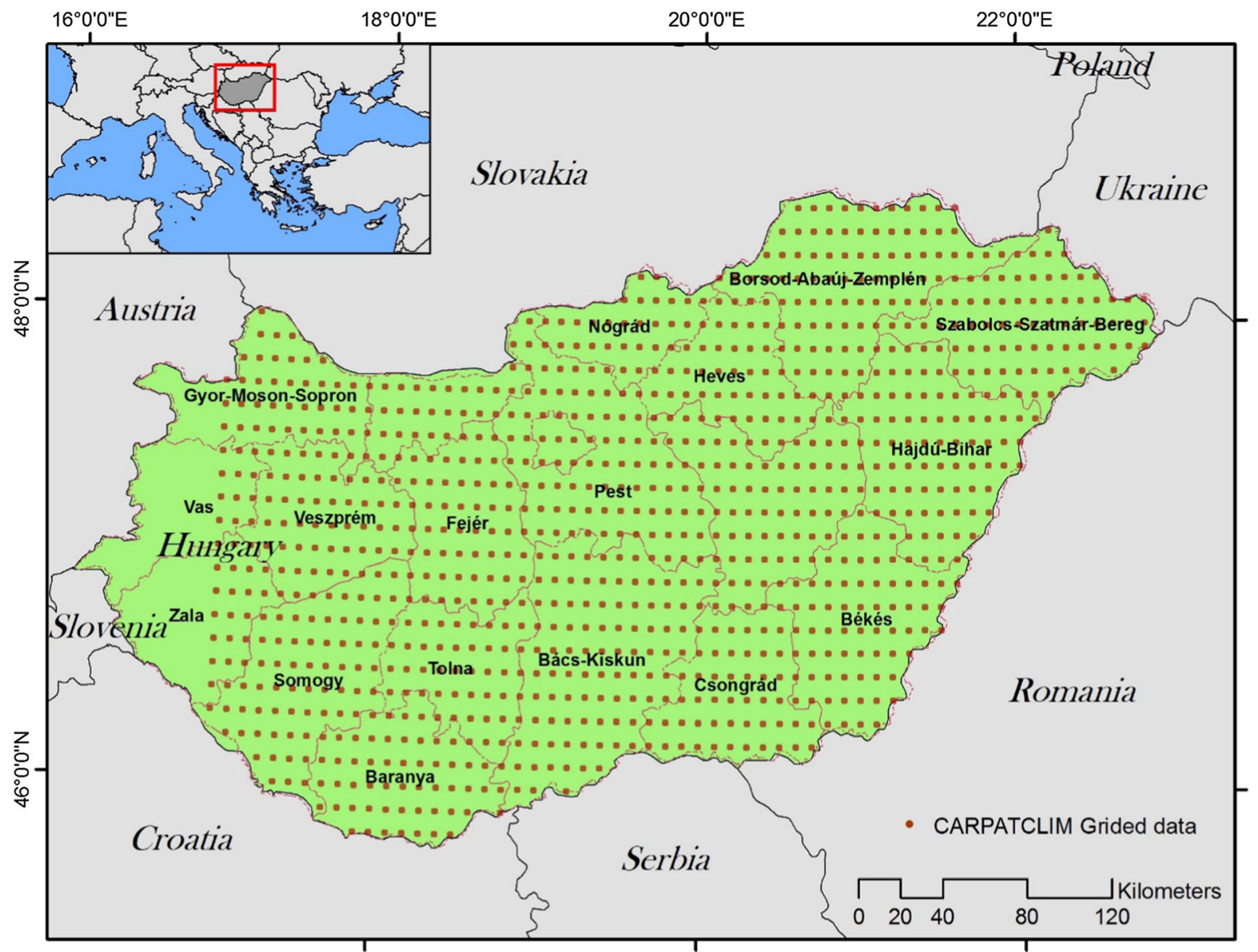

Figure 1

The study area and gridded points from the CARPATCLIM dataset

Table 1

Drought categories based on Agnew's scheme (2000)

\begin{tabular}{ll}
\hline SPI and SPEI values & Drought category \\
\hline$>0$ & No drought \\
0 to -0.5 & Mild drought \\
-0.5 to -0.84 & Moderate drought \\
-0.84 to -1.28 & Severe drought \\
-1.28 to -1.65 & Extreme drought \\
$>-1.65$ & Very extreme drought \\
\hline
\end{tabular}

Table 1 . The positive values indicate wet conditions, while negative values indicate drought conditions (less than median rainfall) (Bordi and Sutera 2001). Interestingly, the SPEI is superior to the SPI in term of drought characterization and climate change monitoring due to the fact that the SPEI takes into consideration both temperature and soil moisture content (used to compute PET) (Spinoni et al. 2013; $\mathrm{Li}$ et al. 2012). Nevertheless, it is important to mention here that the data obtained (i.e. SPEI-12 and SPI-12) were computed by performing a Gamma distribution (shifted version) for easy comparison between the SPI and the SPEI. Paerson III and loglogistic distribution are similarly performed. However, the shifted Gamma distribution method were chosen to compare the SPI and the SPEI in the best way (Spinoni et al. 2013).

The well-known non-parametric Mann-Kendall (MK) statistical test (Kendall 1975; Mann 1945) is frequently used to detect trends in hydro-meteorological time series (i.e. rainfall, temperature, drought indicators, etc.) (Tan et al. 2015; Tian and Quiring 
2019). The MK test is used because it is not affected by outliers and is robust for trends detection with non-normally distributed temporal data (Önöz and Bayazit 2003). Further information about the $\mathrm{M}-\mathrm{K}$ test can be found in Kumar et al. (2009). In our study we used the MK test to detect whether there is statistically significant increasing or decreasing trends in the SPI-12 and SPEI-12 time series at the 95\% confidence level. As many scholars (e.g. Tan et al. 2015; Tian and Quiring 2019) indicate results of an MK test may be affected by autocorrelations of the time series. Thus, pre-whitening was applied before conducting the MK test to reduce the effects of the autocorrelation on the trend detection. This method removes the influence of serial correlation from the time series (Yue and Wang 2002). Herein, this procedure produced the same result. On other hand, the trends magnitude or the time series extent of the SPI and the SPEI was determined using Theil-Sen slope estimator (Thiel 1950; Sen 1968). In the final step, the results of the MK trend test for the SPI and the SPEI time series were keyed to ArcMap software to produce spatial distribution of the gridded points that show significant trends, as well as the decadal changes of the SPI/SPEI-12.

\subsection{Temporal and Spatial Variability of Drought}

In order to identify the common temporal variability and patterns of drought, the principle component analysis (PCA) in S-mod was applied to the SPI-12 and SPEI-12 time series (Rencher 1998). PCA is a non-parametric multivariate technique which reduces the observed variables to a few newly reproduced representative data values called principal components (PCs). The first PC has the highest variance, while the second represent the second highest, and so on. Thus, the first leading components of PCs contain the highest values of the total variance. Such a transformation is a linear one and depends on the eigenvectors of a covariance or correlation matrix (Mathbout et al. 2018; Xie et al. 2013).

In order to produce more localized spatial regions, the Varimax orthogonal rotation method was applied to the "loadings" (the correlation matrix between the SPI time series at single stations and the corresponding PCA); because it simplifies the structure of the patterns by forcing the value of the loading coefficients towards zero or \pm 1 (Hannachi et al. 2007; Raziei et al. 2009; Tian and Quiring 2019). In the next step, the loadings scores were illustrated using ArcGIS software as a thematic map (i.e. after rotation, each SPI/SPEI grid point was assigned to the PCs on which it has the highest correlation or loadings). Final step involved converting the gridded vector points to raster layer at same spatial resolution, without using the interpolation techniques.

\subsection{Total Drought Duration (TDD) and Spatial Extent}

Drought duration is defined as a total number of months when the SPI/SPEI is less than 0 for a specific continuous period (Wang et al. 2014; Tan et al. 2015). While, the total drought duration (TDD) is expressed for all drought events where SPI/SPEI is $<0$ over the whole study period $\mathrm{N}_{\mathrm{i}}$ or for different drought categories (i.e. to study the drought frequencies with different intensity (Guo et al. 2017; Fang et al. 2018). For example, a mild TDD is computed with a calculation involving the total number of months in which $-0.84<$ SPI/SPEI $<-0.5$ either for the whole studied period or for a short period i.e. a specific drought episode as follows:

$$
\operatorname{TDD}(\%)=\frac{n_{i}}{N_{i}} \times 100
$$

where $n_{i}$ is the number of drought events, $N_{i}$ is the total number of months for the study period, and $i$ is a studied location.

The drought-prone areas were examined by the percentage of the number of drought locations in the total study area (\%) for different drought categories. Therefore, it indicates the percentage of area affected by drought (Li et al. 2012; Tan et al. 2015) as follows:

$$
\operatorname{SEoD}(\%)=\frac{m_{i}}{M_{i}} \times 100
$$

The SEoD is the spatial extent of the drought, where $\mathrm{i}$ is a month, $\mathrm{m}_{\mathrm{i}}$ is the number of drought points when the SPI/SPEI is $<0$, or for a specific intensity in month $\mathrm{i}$, and $\mathrm{M}_{\mathrm{i}}$ is the total number of points included. 


\section{Results}

\subsection{Drought: SPI-12 and SPEI-12 Trends}

To track drought episodes in Hungary, the SPI12 and the SPEI-12 were analyzed for the 1045 gridded points by using the $\mathrm{M}-\mathrm{K}$ test. Results indicate a significant negative SPI-12 trend $(\mathrm{P}<0.05)$ at 121 gridded points $(11.5 \%$ of the total points) over the western part of Hungary (Fig. 2), while 359 gridded points (34.4\% of the total points) show a significant positive trend $(\mathrm{P}<0.05)$ over the eastern part; nonetheless, no trend was detected in the rest of the studied points. Although the total number of SPEI-12 time series gridded points with a significant trend were 457 (i.e. $43.7 \%$ of the total points), only 5 points had a significant positive trend, and $452(98.9 \%)$ showed a significant negative trend $(\mathrm{P}<0.05)$ (Fig. 2). Noticeably, Fig. 2 depicts the dynamic role of temperature through the SPEI-12 index, which contributed appreciably to amplifying and magnifying drought over Hungary. Strictly speaking, negative changes per decade (i.e. drought tendency) were extended towards the western part of Hungary and covered almost $60 \%$ of the territory. Nonetheless, the significant negative SPI-12 and SPEI-12 trends remained concentrated in the eastern and middle parts of the country.

\subsection{Drought: SPI-12 and SPEI-12 Spatial Pattern in Hungary}

The PCA analysis was applied to the SPI-12 and the SPEI-12 time series [in geoscience, this analysis is also called the empirical orthogonal function (EOF) analysis]. Following this, the first six components (PCs) account for $91.7 \%$ and $92 \%$ of the total variance for the SPI-12 and the SPEI-12, respectively (Figs. 3, 4).

For the SPI, the first principle component (PC1) makes the largest contribution to the total variance (28.5\%), followed by the PC2 (24.8\%), then the rest of the PCs-i.e. PC3, PC4, PC5, PC6-which contributed $18.9 \%, 17.2 \%, 1.4 \%$ and $0.9 \%$, respectively (Fig. 3).

Figure 5 demonstrates the spatial distribution of the rotated loading for each drought index (i.e. the SPI and the SPEI), suggesting that Hungary is composed of six different sub-sets; characterized by different drought variability. However, PC1 dominates in the western part of Hungary which covers the Transdanubia region (Central Transdanubia, Western Transdanubia, Southern Transdanubia); Interestingly, this pattern occurs in Fig. 2, which has a significant negative trend according to the $\mathrm{M}-\mathrm{K}$ test (see Figs. 2, 5, PC1). On the other hand, PC2 dominates in the eastern part of Hungary (Northern Hungary and Northern Great Plain), as is shown in Fig. 5, where it explained about $8.9 \%$ of the SPIs'
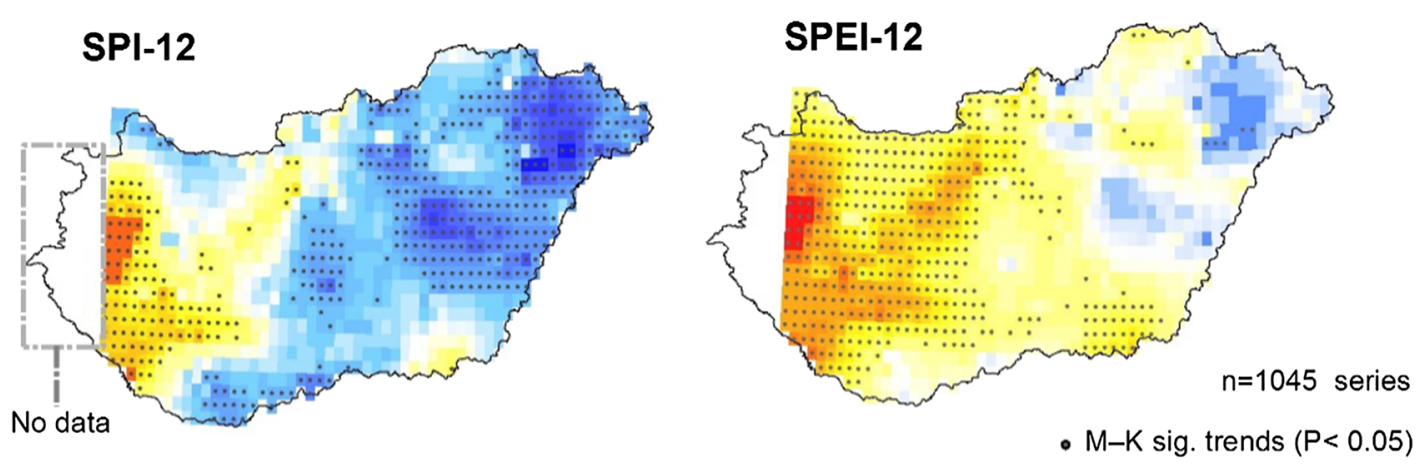

Z unit per/decade

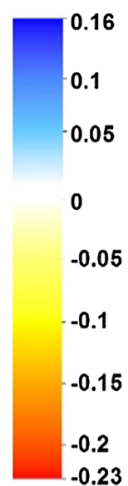

Figure 2

The SPI/SPEI-12 Sen's slope estimator (changes per decade), and its trends (M-K statistic test) for Hungarian territory from 1961 to 2010 (black points were statistically had a significant trend at $\mathrm{P}<0.05$ ) 


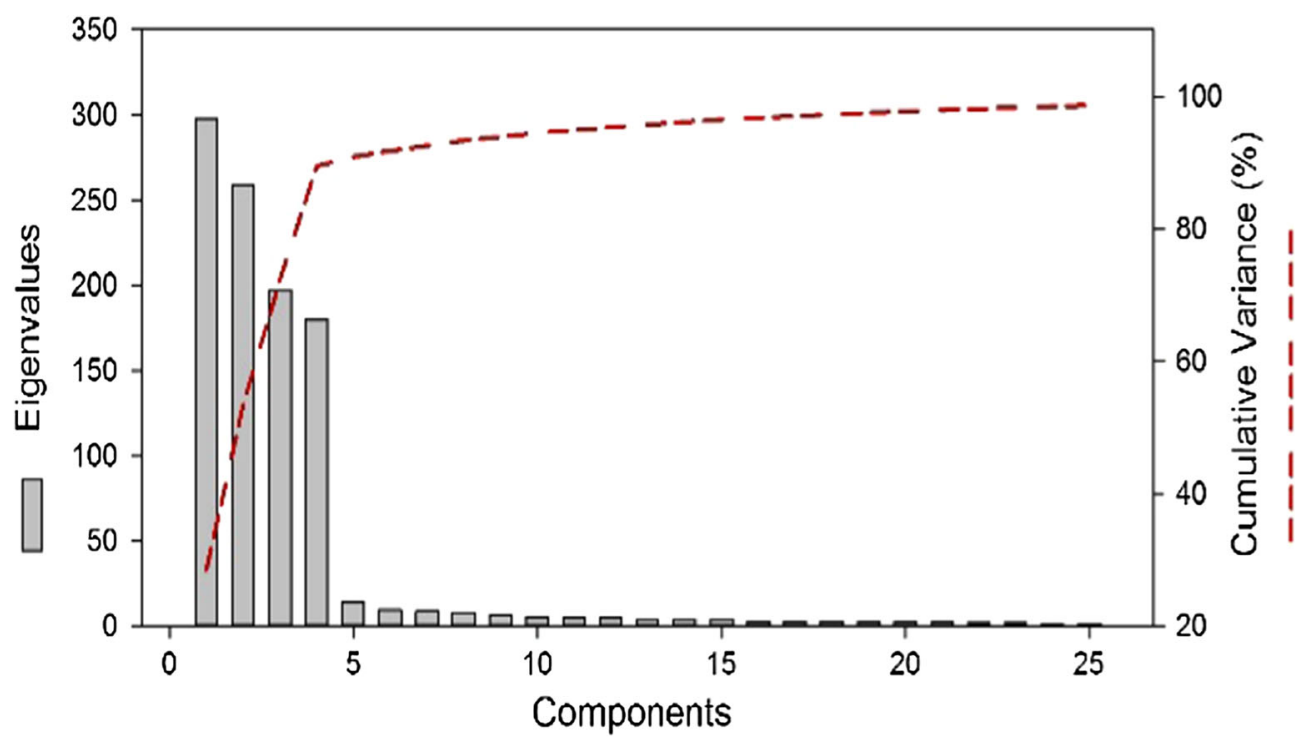

Figure 3

Cumulative variance explained by the different components of the PCA results in S-mode for SPI series

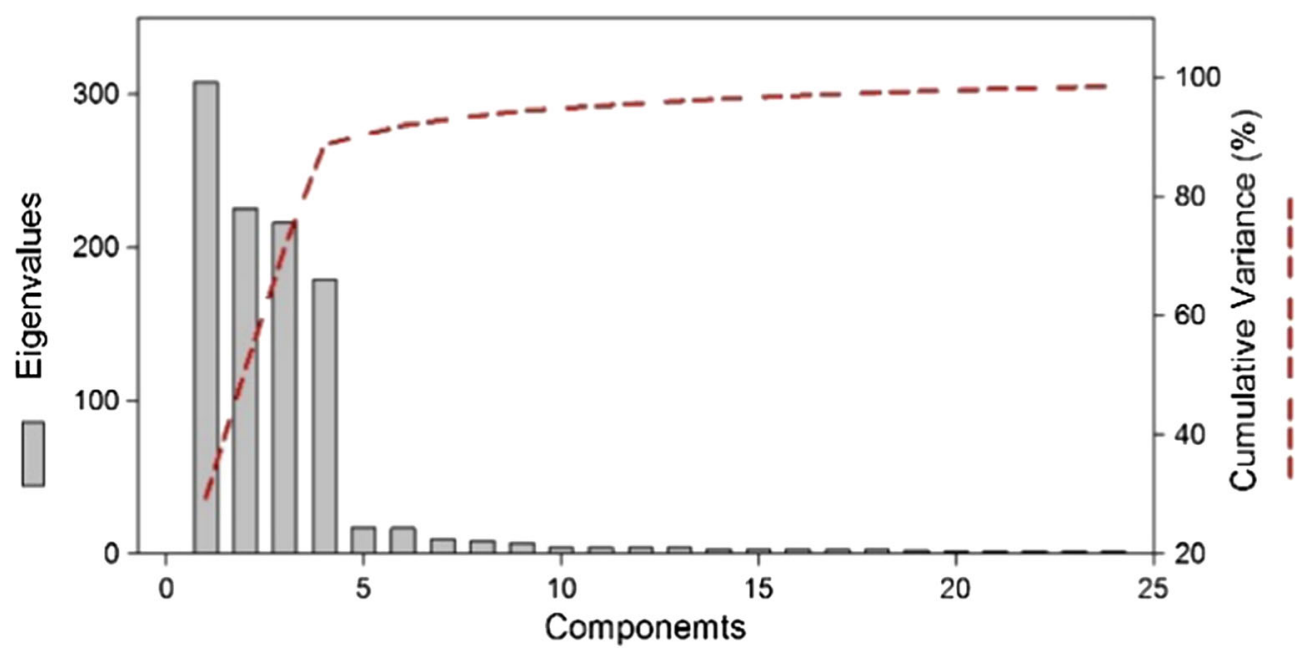

Figure 4

Cumulative variance explained by the different components of the PCA results in S-mode for SPEI series

total variance. This pattern covers the subregion that has a significant positive trend according to the $\mathrm{M}-\mathrm{K}$ test (Figs. 2, 5, PC2). PC3 dominates in the southern part of the country (Southern Great Plain), and PC4 the northern part (Central Hungary), while PC5 features in the southern part of the Southern Transdanubia region (near to the Croatian border), and PC6 covers the city of Györ, in the far northwest near the Slovakian border.
For the SPEI, the first principle component (PC1) makes the greatest contribution to the total variance (29.4\%), followed by PC2 $(21.5 \%)$, and then by the rest of the PCs-i.e. PC3, PC4, PC5, PC6-which contributed $20.7 \%, 17.1 \%, 1.7 \%$ and $1.6 \%$, respectively (Fig. 4).

As is shown in Fig. 5, PC1 dominates in the western part of Hungary which covers the Transdanubia region (Central Transdanubia, Western 


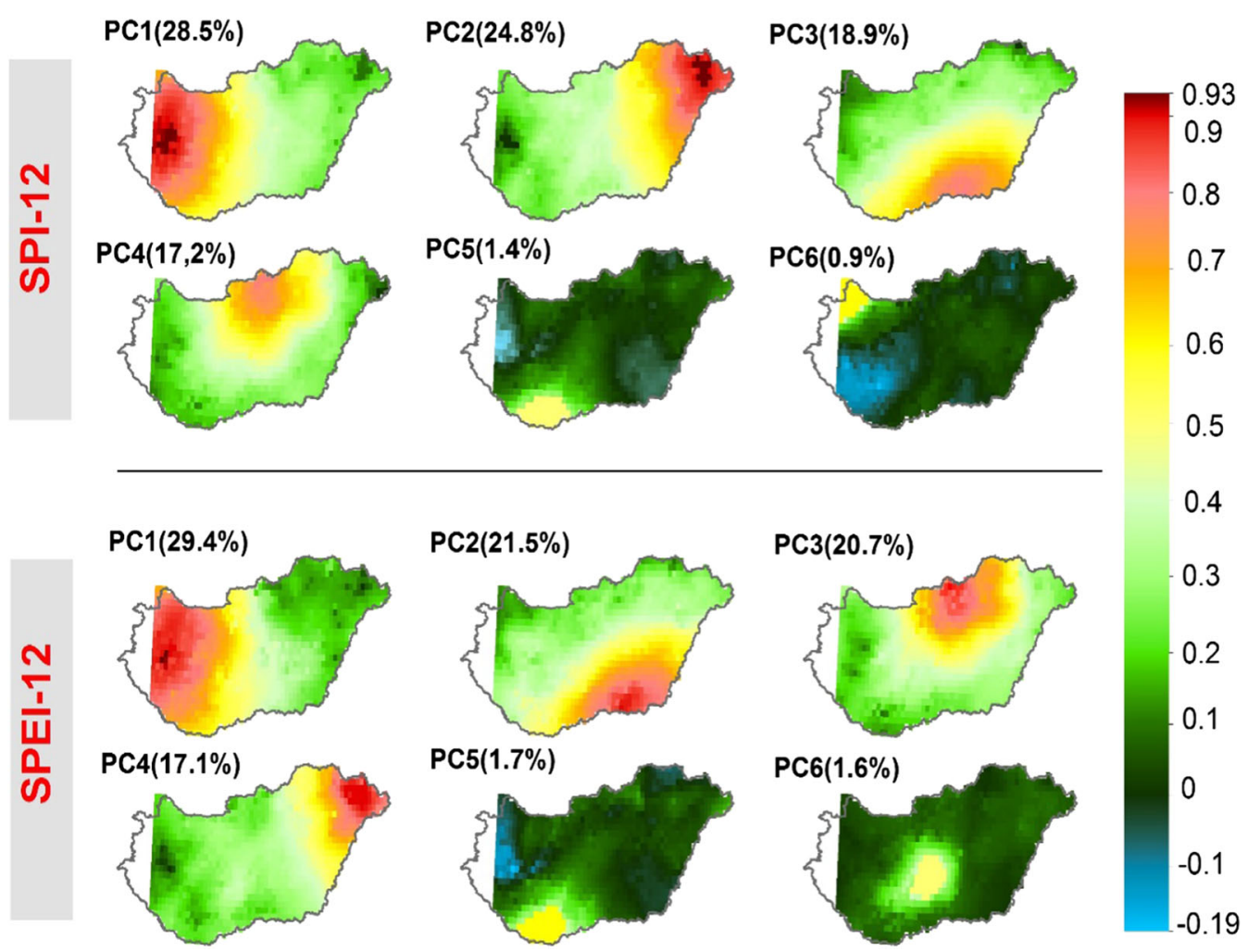

Figure 5

the SPI-12 and the SPEI-12 relative to Varimax rotated loadings for the studied points

Transdanubia, Southern Transdanubia), while PC2 dominates in the southern part (Southern Great Plain) and PC3 in the northern part (Northern Hungary). PC4 dominates in the eastern part of Hungary (Northern Hungary and Northern Great Plain), PC5 in the southern part of the Southern Transdanubia region (near to the Croatian border), while PC6 covers Central Hungary.

To investigate further the vulnerability of the various sub-regions to different classes of drought, the spatial-temporal evolution of both the SPI-12 and the SPEI-12 and the occurrence of drought were assessed from the PC scores during the period 1961-2010, as can be seen in Figs. 6 and 7. Following this, the results showed different susceptibilities to drought among different components for both indices.

For the SPI-12, only PC1 showed a significant decline $(\mathrm{P}<0.05)$ in SPI values $(-0.13$ unit/ decade), as illustrated in Fig. 6, which indicates the increase in drought intensity over the Transdanubia region. However, the rest of the PCs/sub-sets (i.e.
PC2, PC3, PC4, PC5, and PC6) were less vulnerable to drought as the SPI values had increased. Noticeably, this increase was significant $(\mathrm{P}<0.05)$ for $\mathrm{PC} 2$ (0.11 unit/decade), PC5 (0.17 unit/decade), and PC6 (0. 13 unit/decade) (Fig. 6).

Similarly, PC1 (Transdanubia region) and PC6 (Central Hungary) were subjected to significant declines $(\mathrm{P}<0.05)$ in SPEI values during the study period: $-0.17 \%$ per decade $(\mathrm{P}<0.05)$ and -0.13 per decade $(\mathrm{P}<0.05)$, respectively (Fig. 7). In contrast, positive increases in SPEI values (less vulnerable to drought) were identified for PC2, PC3, PC4, and PC5 (Fig. 7). However, these increased values were only significant $(\mathrm{P}<0.05)$ for PC4 (the eastern part of Hungary) and PC5 (Southern Transdanubia region).

\subsection{Total Drought Duration (TDD) Analysis}

In this part of the research, the spatially distributed percentage of the total drought duration TDD 

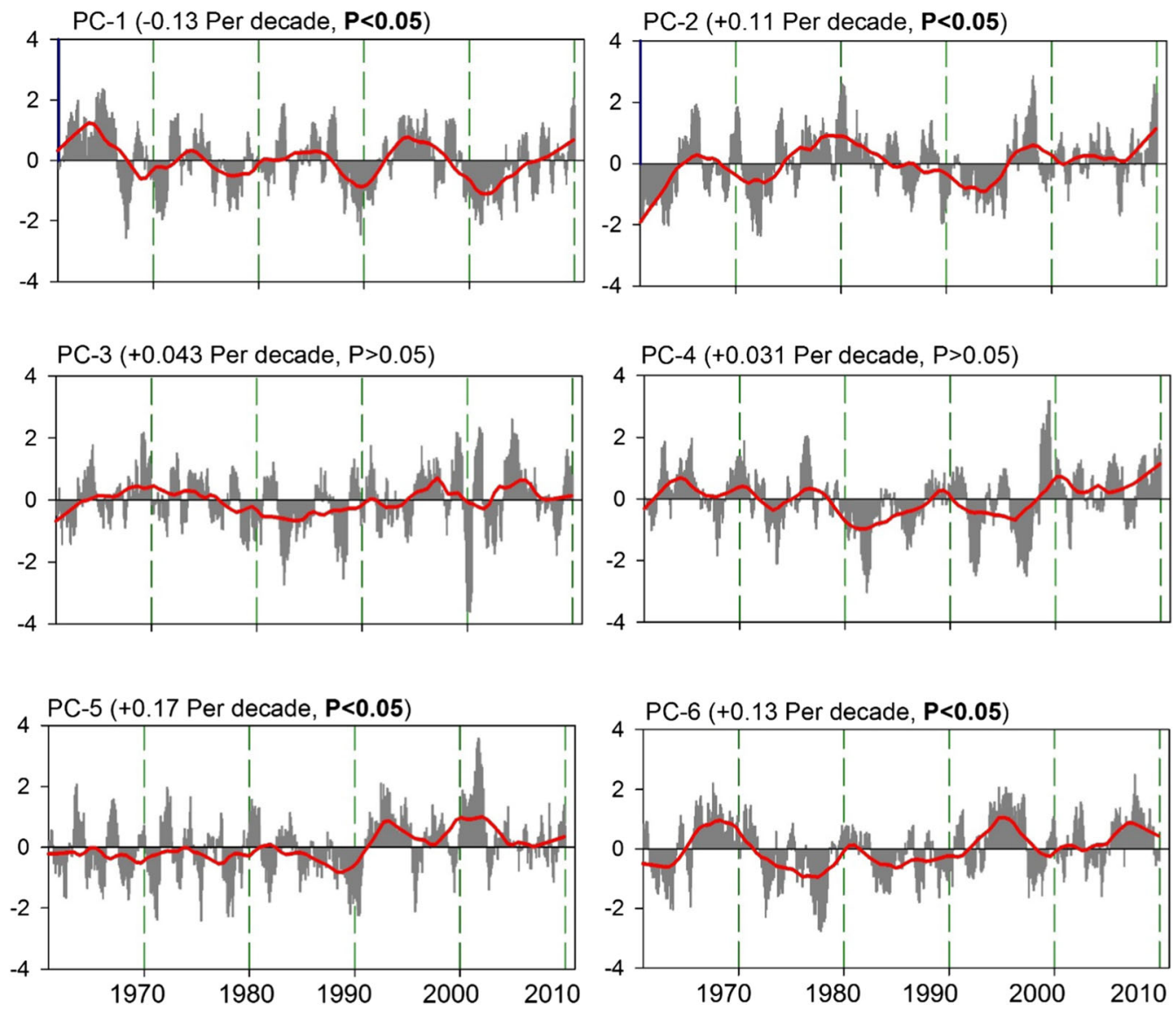

Figure 6

Time evolution of the scores corresponding to PCs that calculated from the series of SPI at 12-time scale, the red line indicates the smoothed series using the polynomial regression and weights from gaussian density function, and the statistically significant changes are given by bold font

on a 12-month time scale was calculated, in order to study the different intensities of drought frequency (see Table 1). Figure 8 illustrates the spatial distribution of total drought (\%) for different drought categories (i.e., no drought, mild, moderate, severe and extreme) on a 12-month time scale.

The spatial distribution of SPI-12 based TDDs indicates that very extreme droughts tend to occur in the southwest of the study area (i.e. Somogy and Baranaya), and in the western of the study area (Veszprém), with values of about 5-7\%, while most of the central parts and the far east of the country are characterized by lower drought frequencies (about $1.5-3 \%$ ) for the same category. Interestingly, the very extreme TDDs have a quite distinctive spatial pattern and high spatial variation, whereas the extreme and severe droughts tend to occur in the central study area (i.e. Jász, Nagykun, Szolnok, and Pest) and in the western part of the study area (Veszprém), and also in the eastern parts of Bács-Kiskun, with values of about $9-7 \%$ for extreme TDDs, and $14-16 \%$ for severe TDDs. Noticeably, the mild and moderate TDD values account for the majority of the total drought duration, and more frequently over the northern and southern west parts of the studied area, but they have a random spread pattern.

On the other hand, the spatial distribution of SPEI-12 based TDDs indicate that very extreme droughts tend to occur in the southwestern (i.e. Somogy and Baranaya) and central parts of the study area (Jász, Nagykun, Szolnok and Pest), as well as in the western part (Veszprém), with values of about $7-8 \%$ for severe TDDs. One of the most striking characteristics is that both indices have the same 

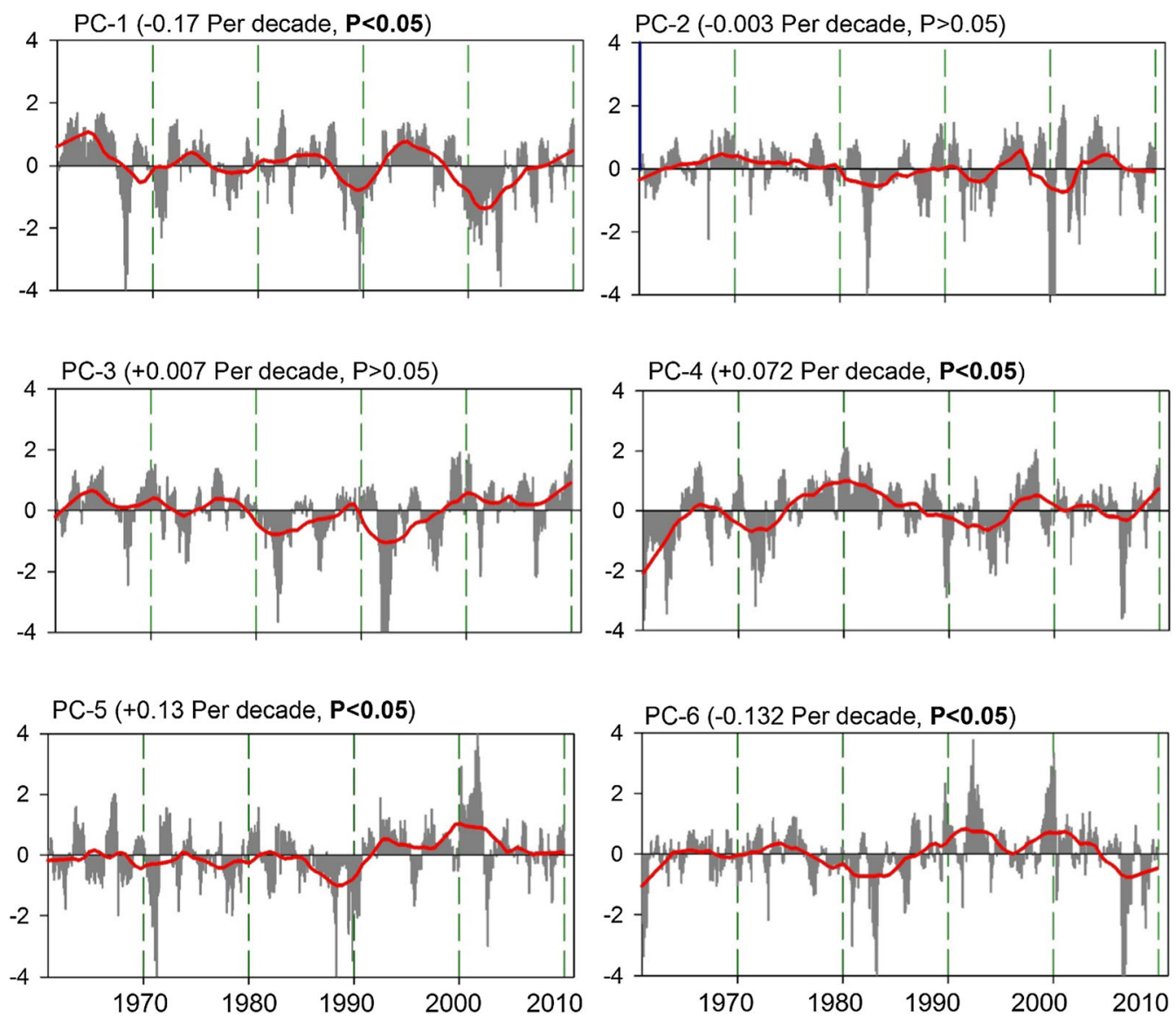

Figure 7

Time evolution of the scores corresponding to PCs that calculated from the series of SPEI at 12-time scale, the red line indicates the smoothed series using the polynomial regression and weights from gaussian density function, and the statistically significant changes are given by bold font

spatial pattern and dominate in almost the same subregions. Figure 9 indicates a positive significant correlation $(\mathrm{r}=0.59, \mathrm{P}<0.05)$ between different types of drought calculated on the basis of TDDsSPIs-12 and TDDs-SPEIs-12 time series over Hungary. Nevertheless, it is worth mentioning here that severe and very extreme droughts are more typical in western and southern regions, while mild drought dominates in the south east of Hungary.

\subsection{Temporal Evolution of the spatial Extent of Drought}

Figure 10 shows the vulnerability of Hungary to different classes of drought. As illustrated, the common groups in Hungary are no drought (SPI/
SPEI $>0$ ), mild drought, and moderate drought (SPI/ SPEI between -1 and -1.49 ), while the other groups are less probable. However, a quick glance at both classes of indices revealed that SPEI was better able to give a general perception of drought evolution over Hungary. Following this, the SPI-12 indicates that no significant change can be detected from 1961 to 2010 over Hungary. However, the "No drought" group was subjected to an increase of +0.9 per decade $(\mathrm{P}>0.05)$, while the "severe drought", "extreme drought" and "very extreme drought" groups decreased by $-0.6 \%$ per decade $(\mathrm{P}>0.05)$, $-0.64 \%$ per decade $(\mathrm{P}>0.05)$, and $-0.22 \%$ per decade $(\mathrm{P}>0.05)$, respectively.

In contrast, the SPEI-12 shows that the drought waves that hit Hungary were more pronounced. 

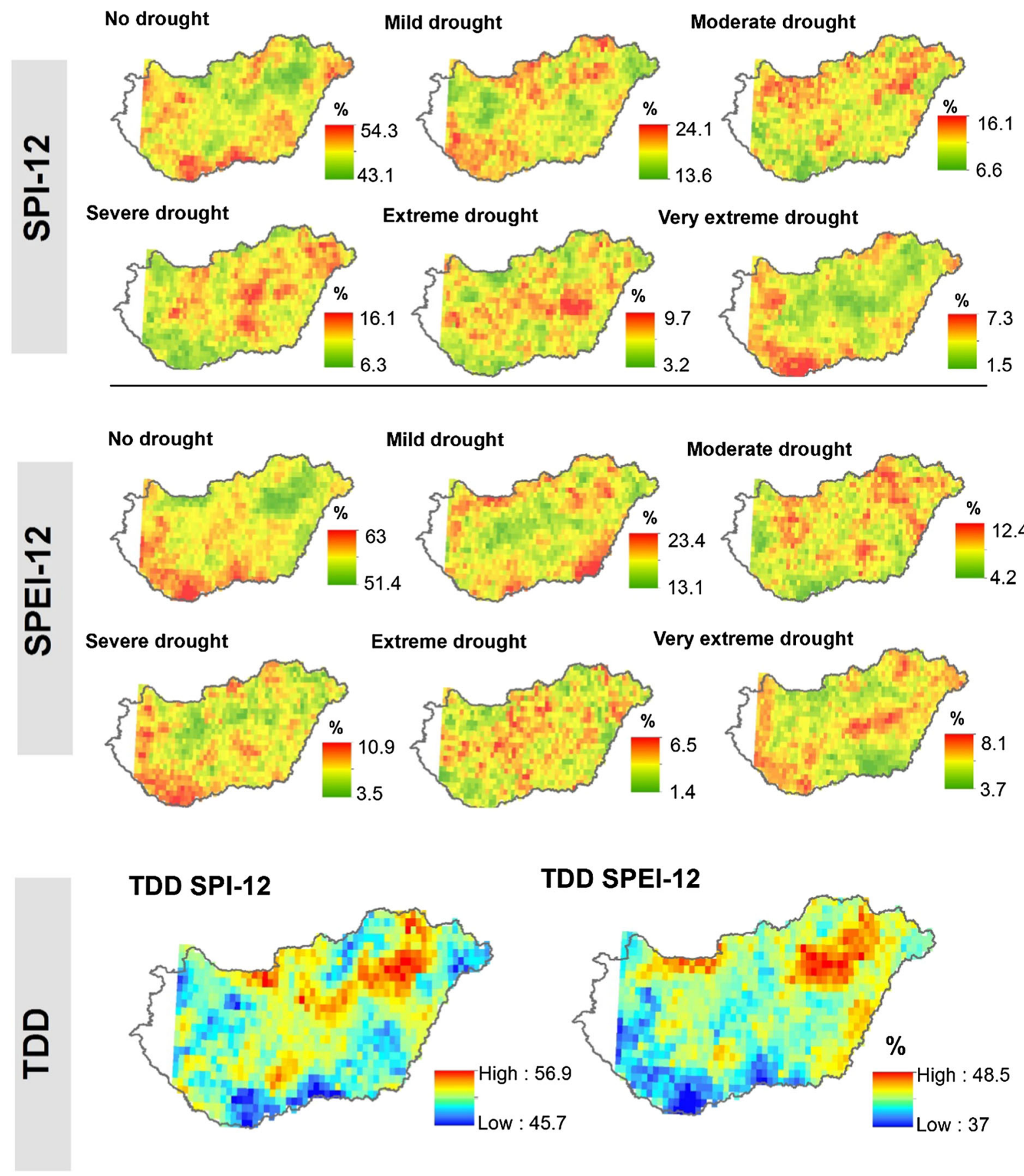

\section{TDD SPI-12}

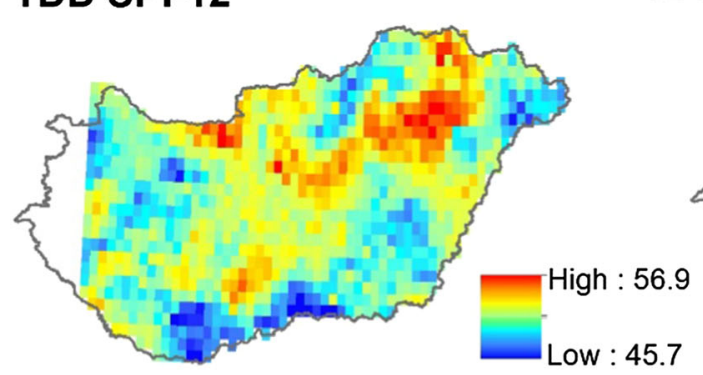

TDD SPEI-12

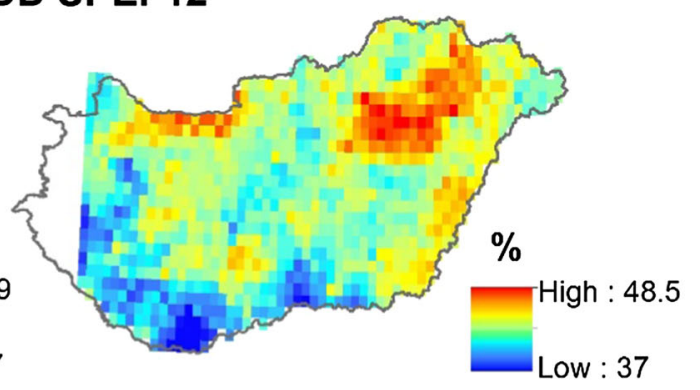

Figure 8

Spatial distribution of total drought duration TDD (number of months \%) at timescales of SPI/SPEI-12 between 1961 and 2010 , for each category of drought, and the TDD calculated for all categories

Although, no significant trend was detected in the SPI-12 categories, it showed that two significant $(\mathrm{P}<0.05)$ different drought categories were detected over Hungary during the study period.
In detail, results suggested a statistically significant decrease $(\mathrm{P}<0.05)$ of $-2.28 \%$ per decade in the area that was not affected by drought (i.e. the "No drought" group). In contrast, a significant positive 


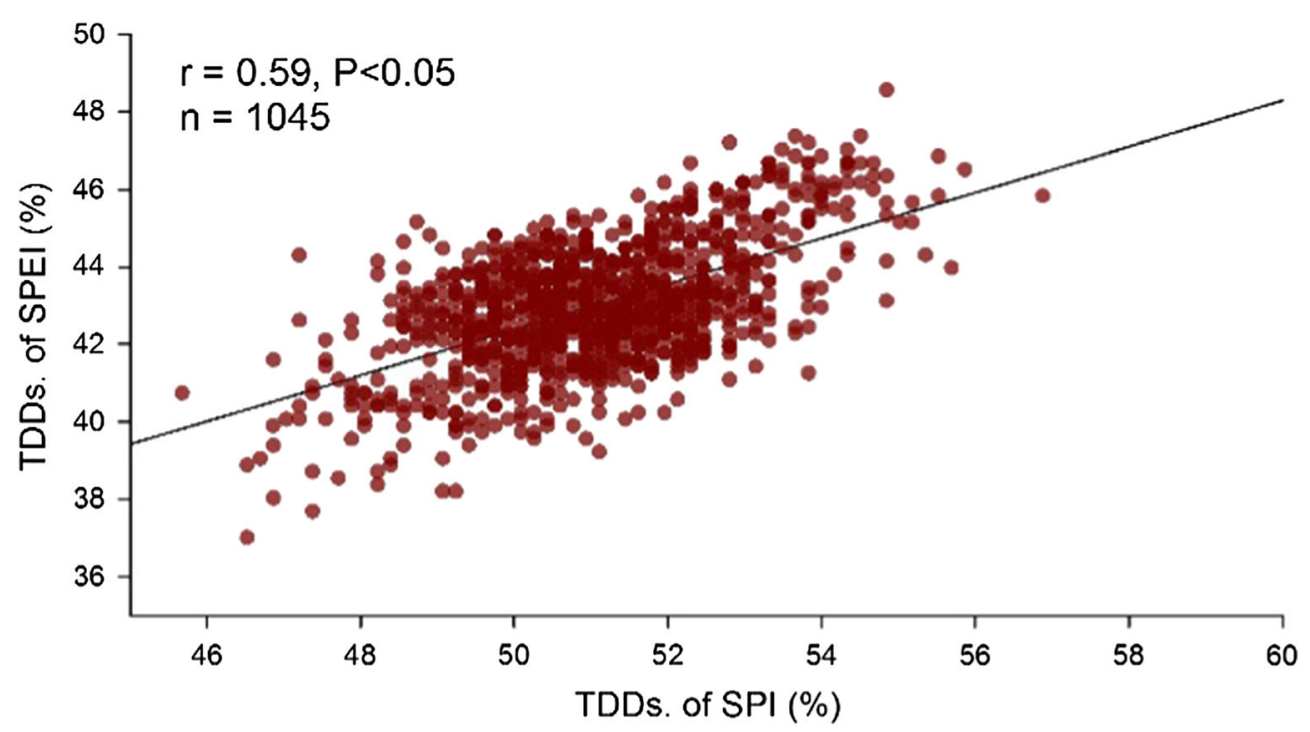

Figure 9

Relationship between TDDs calculated based on the SPIs-12 and the SPEIs-12 time series for spatial extent of whole the studied area ( $\mathrm{n}=1045$ gridded points)

$(\mathrm{P}<0.05)$ trend of $+1.4 \%$ per decade was detected for the area affected by very extreme drought. Even though the changes in the other categories (i.e. "mild", "moderate", "severe", and "extreme") were not significant, they obviously showed a positive trend, which is completely contrary to the calculated results from SPI-12 for the same categories.

Regardless of the significant trends of both indices, we studied the correlation between each group for each indicator (i.e. SPI-spatial extant (\%) and SPEI-spatial extent $(\%)$, as can be seen in Fig. 11). The highest correlation was recorded in the "no drought" group $(\mathrm{r}=0.93)$, followed by the "very extreme" $(r=0.83)$, and "extreme" $(r=0.82)$ groups. Nonetheless, correlation values remain high, indicating the dynamics of two indices in defining drought over space and time.

\section{Discussion}

Drought is one of the normal features of climate that can have a more devastating impact on any ecosystem than any other natural hazard (Pandey et al. 2010; Abbas et al. 2014). Unfortunately, drought is classified as one of the costliest and yet one of the least understood natural disasters (Zhang et al. 2015). A basic understanding of such a phenomenon is an essential step toward building strategies for adaptation and mitigation in any country. Within this context, the main aim of this research was to track drought evolution and drought episodes over Hungary between 1961 and 2010 by using the well-known SPI and SPEI indices for 1045 gridded points obtained from the CARPATCLIM project for climatic data.

The SPI has many disadvantages, such as using only rainfall data, not taking time distribution into account and not being able to predict the starting and ending of a drought cycle (Paltineanu et al. 2009; Wilhite 2000; Vicente-Serrano et al. 2010). The SPEI also has certain disadvantages, such as using the Thornthwaite equation (1948) in the calculation of PET which considers only temperature (Wang et al. 2015), and the fact that heatwaves can be mistaken for metrological drought (Spinoni et al. 2013). Nevertheless, many scholars indicate that monthly rainfall can be perfectly illustrated by using gamma distribution across Europe, and this was used in our study to calculate the SPI-12 and the SPEI-12. Interestingly, Lloyd-Hughes and Saunders (2002) indicate that the SPI-12 results are analogous to those 
SPI-12

No Drought $(+0.9 /$ decade; $P>0.05)$

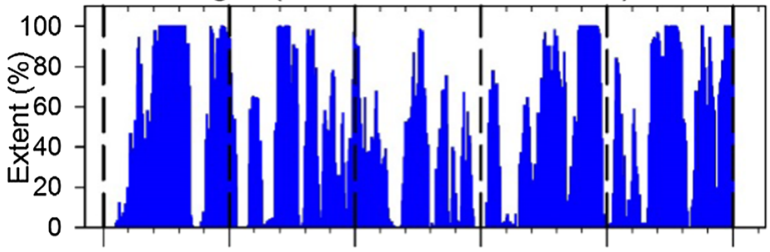

Mild Drought $(+0.36 /$ decade; $P>0.05)$

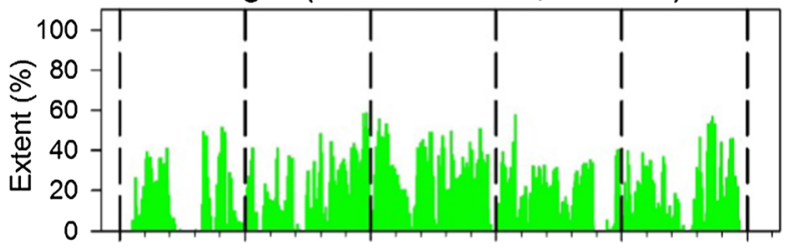

Moderate Drought $(+0.005 /$ decade; $P>0.05)$

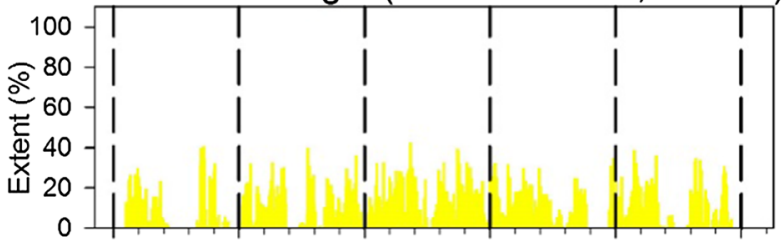

Severe Drought $(-0.6 /$ decade; $P>0.05)$

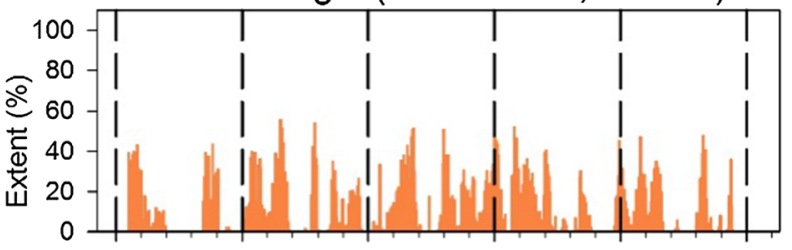

Extreme Drought (-0.46/decade; $\mathrm{P}>0.05)$

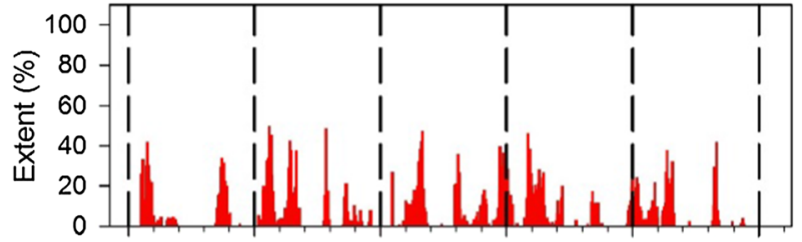

Very Extreme(-0.22/decade; $\mathrm{P}>0.05)$

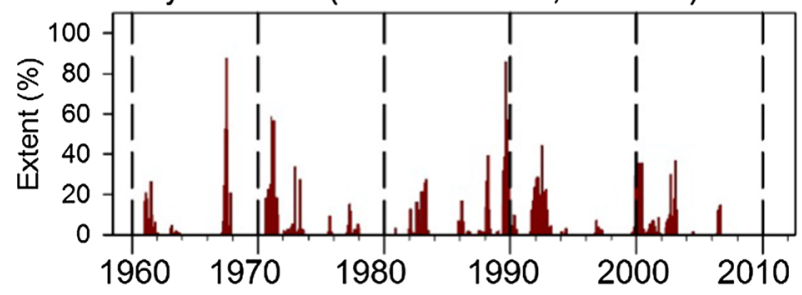

SPEI-12

No Drought $(-2.28 \%$ /decade; $\mathrm{P}<0.05)$

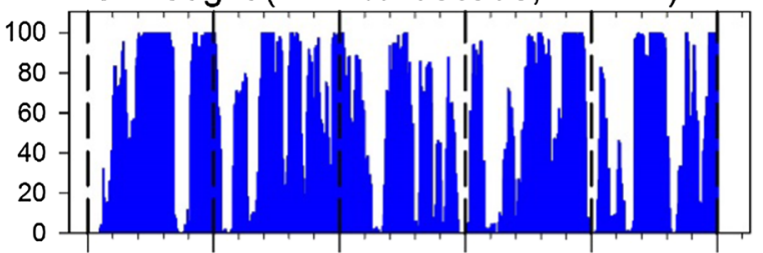

Mild Drought $(+0.23 /$ decade; $P>0.05$ )

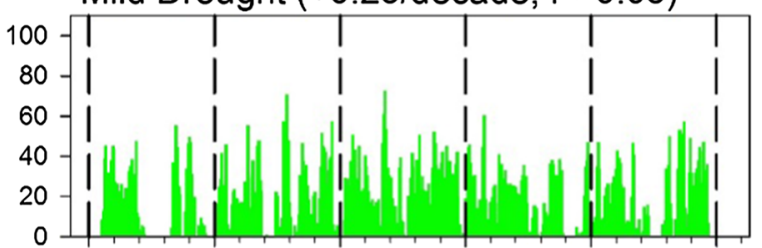

Moderate Drought (+0.08/decade; $\mathrm{P}>0.05$ )

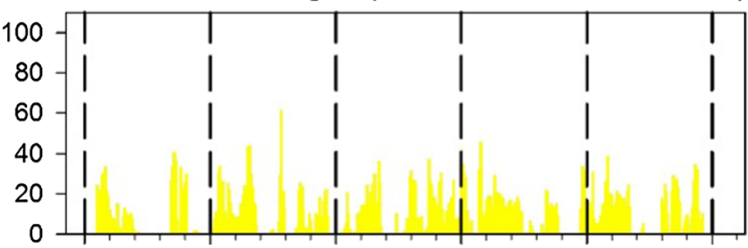

Severe Drought $(+0.19 /$ decade; $P>0.05)$

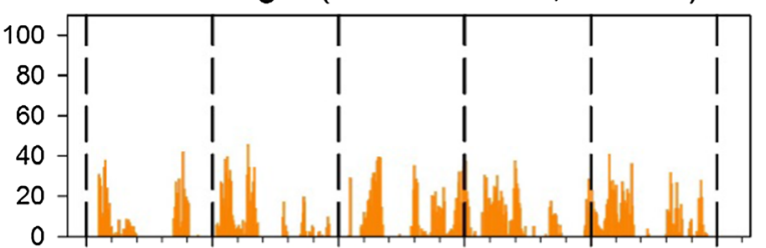

Extreme Drought $(+0.38 /$ decade; $\mathrm{P}>0.05)$

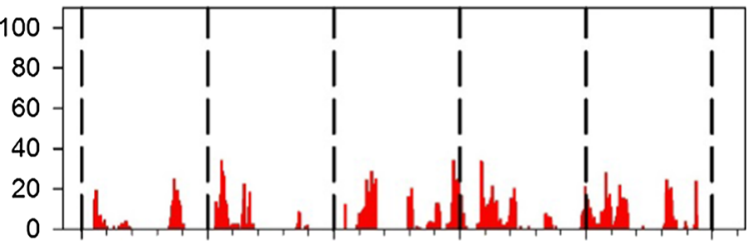

Very Extreme $(+1.4 /$ decade; $P<0.05)$

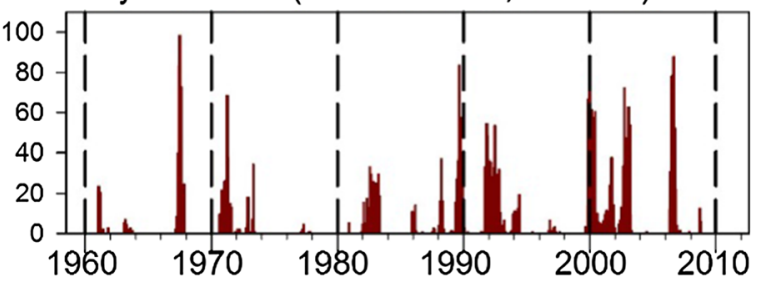

Figure 10

SEoD or temporal evolution of percentage of area affected by different drought categories. Based on SPI/SPEI series at 12-month time scale and spatial extent of the gridded dataset in Hungary 


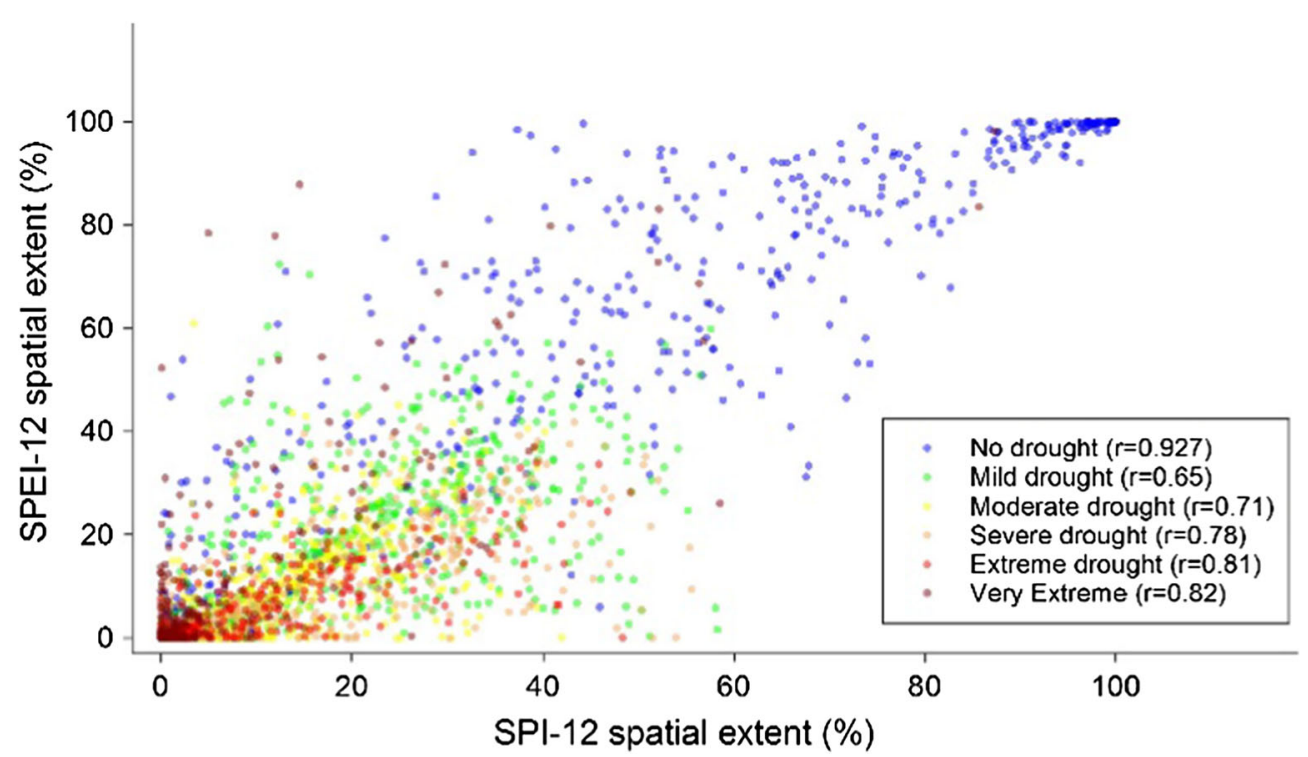

Figure 11

the correlation between SPI-spatial extant (\%) and SPEI-spatial extent during the studied period

obtained from a complicated indicator such as the Palmer drought severity index (PDSI) (Palmer 1965), and superior in terms of spatial standardization. However, the SPEI was designed to integrate the advantages of both the PDSI and the SPI, by considering the effects of precipitation and temperature to assess drought (Vicente-Serrano et al. 2010; Jin et al. 2019).

Comparing the results obtained from both indicators (i.e. the SPI and the SPEI), we find that both indices indicate that the western part of Hungary was more prone to drought, where all of the gridded points showed a significant negative trend. On the contrary, we notice a clear disagreement in determining the significant trends to increased wetness over the eastern part of Hungary. The SPEI indicates that a small portion of eastern Hungary has positive significant trends (only 5 gridded points), while the SPI reveals that 359 gridded points distributed over the eastern part have a positive significant trend. These results can mainly be explained by the differences between the two indices in their drought calculating methodology, whereas using not only precipitation but also the PET significantly affected the results, and revealed more areas that may be prone to drought in Hungary. Indeed, a clear consensus exists among both indicators on two important points. On the one hand, the western part was more vulnerable to drought, where a tendency towards drought (i.e. decreases in SPI-12 and SPEI12 values) was detected for the Transdanubia region (PC1) $(\mathrm{P}<0.05)$. On the other hand, both indices highlighted that the eastern region is less sensitive to drought, as is indicated in PC2 for the SPI-12 and PC4 for the SPEI-12 ( $<$ 0.05). Szabó et al. (2019) found similar results for the period 1961-2010 and reported that the western part of the country was the most sensitive to climate change.

As previously established by many scholars, the evolution, intensity, duration, and end of a drought all mainly depend on precipitation, where rainfall is the key factor in drought determination and evolution within any region (Vicente-Serrano et al. 2010). Therefore, we tracked the decadal precipitation changes (i.e. every 10 years) in Hungary. Following this, the spatial distribution of rainfall changes over Hungary (not shown) reveal that the southern-western part of the study area receives more rainfall than the central part, while the central part (i.e. the Central Hungary region) was more susceptible to rainfall changes which indicate that the central part of Hungary was more prone to drought. However, this result 
should be considered together with the results from Fig. 8 where the spatial distribution of TDDs dominated in the central part of Hungary. In fact, this main difference between the TDD method and the SPI and the SPEI indices in determining drought zones over Hungary can be explained by the fact that TDDs do not consider the temporal consistency of time series and aggregation of drought events, regardless of the time in which they occurred. On the other hand, trend analyses for both the SPI and the SPEI takes into consideration the temporal consistency of drought changes with special focus on the time they occurred. However, Bede-Fazekas and Szabó (2019) indicate that central Hungary-where the average precipitation does not exceed $500 \mathrm{~mm}$-is subjected to drought, and that $90 \%$ of Hungary is prone to drought, with exception of the northern area. In a similar vein, Makra et al. (2005) reported a reduction in rainfall and a tendency to increases in temperature of between 0.4 and $0.8{ }^{\circ} \mathrm{C}$ in Hungary, and that drought will be more frequent in the second half of the 21st century, not only in Hungary but also in the Carpathian Basin as a whole (Pongrácz et al. 2014). This supports our results in Figs. 2 and 10, which shows that extreme and very extreme drought events were more frequent in the last decade, namely from 2000 to 2003 and in 2007. Moreover, Mezősi et al. (2016) supports our results and reported that the last decade (i.e. 2001-2011) was a historically extraordinary decade with two heavy drought events in the south-eastern part of the Carpathian Basin.

Drought in Hungary is one of the aspects of global climate change that could mainly be affected by various atmospheric factors such as the El NiñoSouthern Oscillation (ENSO), the North Atlantic Oscillation (NAO), the Greenland-Balkan Oscillation (GBO) and the Pacific decadal oscillation (PDO). However, Mares et al. (2016) demonstrate that the role of the Greenland-Balkan Oscillation (GBO) in influencing the south-east European hydro-climatic regime is greater than that of the NAO and the ENSO. In particular, the GBO captures both movements of air masses with a meridional component and a zonal component, while the ENSO and the NAO were less dominant in the Danube middle basin (Mares et al. 2016). In a similar vein, Bartholy et al. (2013) emphasized that the most significant factors affecting drought trends in Hungary are atmospheric circulation, lack of precipitation, changes in soil moisture and evapotranspiration and other elements of the hydrological cycle.

\section{Conclusions}

This research tracked the trends, intensity, spatial extent and duration of droughts in Hungary between 1961 and 2010 using 1045 gridded points collected from the Climate of the Carpathian region projectCARPATCLIM by using the SPI and the SPEI.

The results demonstrate that the eastern part of Hungary was less vulnerable to drought, while the western part was more prone to drought. Such results stress the importance of climate mitigation plans which should be prepared on a sub-regional scale, taking into consideration the sustainability of the ecosystems in each one.

\section{Acknowledgements}

Open access funding provided by University of Debrecen (DE). The research was financed by the Higher Education Institutional Excellence Programme (NKFIH-1150-6/2019) of the Ministry of Innovation and Technology in Hungary, within the framework of the 4th thematic programme of the University of Debrecen, and the projects "GINOP2.2.1-15-2016-00001- Developing a scale independent complex precision consultancy system" and "EFOP-3.6.3-VEKOP-16-2017-00008". The authors grateful for Debrecen Universities for their unlimited support and open access funding. Authors also thank the CARPATCLIM team for data sharing. A special thanks extend to Prof. Dr. Nagy János (Head of Kerpely Kálmán Doctoral School) for his unlimited support.

Open Access This article is licensed under a Creative Commons Attribution 4.0 International License, which permits use, sharing, adaptation, distribution and reproduction in any medium or format, as long as you give appropriate credit to the original author(s) and the source, provide a link to the Creative Commons licence, and indicate if changes were made. The images or other third party material in this article are included in the article's Creative Commons licence, unless indicated otherwise in a credit line to the 
material. If material is not included in the article's Creative Commons licence and your intended use is not permitted by statutory regulation or exceeds the permitted use, you will need to obtain permission directly from the copyright holder. To view a copy of this licence, visit http://creativecommons.org/licenses/by/4. $0 /$.

\section{Publisher's Note Springer Nature remains neutral} with regard to jurisdictional claims in published maps and institutional affiliations.

\section{REFERENCES}

Abbas, S., Nichol, J., Qamer, F., \& Xu, J. (2014). Characterization of drought development through remote sensing: A case study in Central Yunnan, China. Remote Sensing, 6(6), 4998-5018.

Ács, F., Breuer, H., \& Skarbit, N. (2015). Climate of Hungary in the twentieth century according to Feddema. Theoretical and Applied Climatology, 119(1-2), 161-169.

Agnew, C. T. (2000). Using the SPI to identify drought. Drought Network News, 12, 6-12.

Anyamba, A., \& Tucker, C. J. (2012). Historical perspective of AVHRR NDVI and vegetation drought monitoring. Remote Sensing of Drought: Innovative Monitoring Approaches, 23, 20.

Ayugi, B., Tan, G., Niu, R., Dong, Z., Ojara, M., Mumo, L., Hassen, B., \& Ongoma, V., 2020. Historical Characterization of historical trends of droughts and pluvial scenarios over Kenya, East Africa. Preprints. 2019. https://doi.org/10.20944/ preprints201912.0343.v1.

Bartholy, J., Pongrácz, R., \& Hollósi, B. (2013). Analysis of projected drought hazards for Hungary. Advances in Geosciences, 35, 61-66.

Bede-Fazekas, Á., \& Szabó, K. (2019). Predicting future shift of drought tolerance zones of ornamental plants in Hungary. Idöjárás/Quarterly Journal of The Hungarian Meteorological Service, 123(1), 107-126.

Bezdan, J., Bezdan, A., Blagojević, B., Mesaroš, M., Pejić, B., Vranešević, M., et al. (2019). SPEI-based approach to agricultural drought monitoring in Vojvodina Region. Water, 11(7), 1481.

Bihari, Z., \& Szentimrey, T. (2013). Final Version of Metadata per Country of All National Gridded Datasets Created within Module 2. Annex 3 - Description of MASH and MISH Algorithms, Deliverable D2.10. CarpatClim. http://www.carpatclim-eu.org/ docs/mashmish/mashmish.pdf. Accessed Sept 2018

Blanka, V., Mezősi, G., \& Meyer, B. (2013). Projected changes in the drought hazard in Hungary due to climate change. Időjárás, 117(2), 219-237.

Bordi, I., \& Sutera, A. (2001). Fifty years of precipitation: Some spatially remote teleconnnections. Water Resources Management, 15(4), 247-280.

Breuer, H., Ács, F., \& Skarbit, N. (2017). Climate change in Hungary during the twentieth century according to Feddema. Theoretical and Applied Climatology, 127(3-4), 853-863.

Bussay, A., \& Szinell, C. (1996). Drought continues in Hungary in 1995. Drought Network News (1994-2001), Vol. 11. http:// digitalcommons.unl.edu/droughtnetnews.
Caloiero, T., \& Veltri, S. (2019). Drought assessment in the Sardinia Region (Italy) during 1922-2011 using the standardized precipitation index. Pure and Applied Geophysics, 176(2), 925-935.

CARPATCLIM. (2019). Climate of the Carpathian region project. http://www.carpatclim-eu.org/pages/about/. Accessed Oct 2019.

CARPATCLIM, Climate of the Carpathian region project. (2012). Final report on quality control and data homogenization measures applied per country, including QC protocols and measures to determine the achieved increase in data quality, Deliverable D1.12. http://www.carpatclim-eu.org/docs/deliverables/D1_12. pdf. Accessed Oct 2019.

Chang, K. Y., Xu, L., \& Starr, G. (2018). A drought indicator reflecting ecosystem responses to water availability: The normalized ecosystem drought index. Agricultural and Forest Meteorology, 250, 102-117.

EEA. (2009). Water resources across Europe-confronting water scarcity and drought (EEA Report No. 2). Copenhagen: European Environment Agency (EEA), Office for Official Publications of the European Communities (OPOCE).

EEA. (2017). Climate change impacts and vulnerability in Europe (EEA Report No 1/2017). Copenhagen: European Environment Agency (EEA), Office for Official Publications of the European Communities (OPOCE).

Fang, Y., Qian, H., Chen, J., \& Xu, H. (2018). Characteristics of spatial-temporal evolution of meteorological drought in the Ningxia Hui Autonomous Region of Northwest China. Water, 10(8), 992.

Feyen, L., \& Dankers, R. (2009). Impact of global warming on streamflow drought in Europe. Journal of Geophysical Research: Atmospheres, 114, D17.

Fiala, K., Blanka, V., Ladányi, Z., Szilassi, P., Benyhe, B., Dolinaj, D., et al. (2014). Drought severity and its effect on agricultural production in the Hungarian-Serbian cross-border area. Journal of Environmental Geography, 7(3-4), 43-51.

Gálos, B., Lorenz, P., \& Jacob, D. (2007). Will dry events occur more often in Hungary in the future? Environmental Research Letters, 2(034006), 9.

Guo, H., Bao, A., Liu, T., Ndayisaba, F., He, D., Kurban, A., et al. (2017). Meteorological drought analysis in the Lower Mekong Basin using satellite-based long-term CHIRPS product. Sustainability, 9(6), 901.

Hannachi, A., Jolliffe, I. T., \& Stephenson, D. B. (2007). Empirical orthogonal functions and related techniques in atmospheric science: A review. International Journal of Climatology: A Journal of the Royal Meteorological Society, 27(9), 1119-1152.

Hernandez, E. A., \& Uddameri, V. (2014). Standardized precipitation evaporation index (SPEI)-based drought assessment in semi-arid south Texas. Environmental Earth Sciences, 71(6), 2491-2501.

Hernández-Morcillo, M., Burgess, P., Mirck, J., Pantera, A., \& Plieninger, T. (2018). Scanning agroforestry-based solutions for climate change mitigation and adaptation in Europe. Environmental Science and Policy, 80, 44-52.

Horvath, S. Z., Makra, L., \& Mika, J. (2005). 20th Century variations of the soil moisture content in east Hungary. Acta Climatologica et Chorologica, Universitatis Szegediensis, 38(39), 85-95.

Jiao, W., Zhang, L., Chang, Q., Fu, D., Cen, Y., \& Tong, Q. (2016). Evaluating an enhanced vegetation condition index (VCI) based 
on VIUPD for drought monitoring in the continental United States. Remote Sensing, 8(3), 224.

Jin, X., Qiang, H., Zhao, L., Jiang, S., Cui, N., Cao, Y., et al. (2019). SPEI-based analysis of spatio-temporal variation characteristics for annual and seasonal drought in the Zoige Wetland, Southwest China from 1961 to 2016. Theoretical and Applied Climatology, 20, 1-15.

Kendall, M. G. (1975). Rank correlation methods, 4th edn. Charles Griffin, London.

Kern, A., Marjanović, H., \& Barcza, Z. (2016). Evaluation of the quality of NDVI3g dataset against collection 6 MODIS NDVI in Central Europe between 2000 and 2013. Remote Sensing, 8(11), 955.

Kertész, Á. D. Á. M. (2016). Is Desertification a problem in Hungary? Acta geographica debrecina. Landscape and Environment, 10(3-4), 242-247.

Kumar, S., Kumar, P., Barat, A., Sinha, A. K., Sarthi, P. P., Ranjan, P., et al. (2019). Characteristics of observed meteorological drought and its linkage with low-level easterly wind over India. Pure and Applied Geophysics, 176(6), 2679-2696.

Kumar, S., Merwade, V., Kam, J., \& Thurner, K. (2009). Streamflow trends in Indiana: Effects of long-term persistence, precipitation and subsurface drains. Journal of Hydrology, 374(1-2), 171-183.

Labudová, L., Labuda, M., \& Takáč, J. (2017). Comparison of SPI and SPEI applicability for drought impact assessment on crop production in the Danubian Lowland and the East Slovakian Lowland. Theoretical and Applied Climatology, 128(1-2), 491-506.

Li, Y. J., Zheng, X. D., Lu, F., \& Ma, J. (2012). Analysis of drought evolvement characteristics based on Standardized Precipitation Index in the Huaihe River Basin. Procedia Engineering, 28, 434-437.

Lloyd-Hughes, B., \& Saunders, M. A. (2002). A drought climatology for Europe. International Journal of Climatology: A Journal of the Royal Meteorological Society, 22(13), 1571-1592.

Makra, L., Mika, J., \& Horváth, S. (2005). 20th century variations of the soil moisture content in East-Hungary in connection with global warming. Physics and Chemistry of the Earth, Parts A/B/ C, 30(1-3), 181-186.

Mann, H. B. (1945). Nonparametric tests against trend. Econometrica: Journal of the Econometric Society, 13, 245-259.

Mares, C., Mares, I., \& Mihailescu, M. (2016). Identification of extreme events using drought indices and their impact on the Danube lower basin discharge. Hydrological Processes, 30(21), 3839-3854.

Mathbout, S., Lopez-Bustins, J. A., Martin-Vide, J., Bech, J., \& Rodrigo, F. S. (2018). Spatial and temporal analysis of drought variability at several time scales in Syria during 1961-2012. Atmospheric Research, 200, 153-168.

McKee, T. B., Doesken, N. J., \& Kleist, J. (1993). The relationship of drought frequency and duration to time scale. Preprints 8th conference on applied climatology (pp. 179-184). Anaheim: American Meteorological Society.

Mezősi, G., Blanka, V., Ladanyi, Z., Bata, T., Urdea, P., Frank, A., et al. (2016). Expected mid-and long-term changes in drought hazard for the South-Eastern Carpathian Basin. Carpathian Journal of Earth and Environmental Sciences, 11(2), 355-366.

Mika, J., Horvath, S. Z., Makra, L., \& Dunkel, Z. (2005). The Palmer Drought Severity Index (PDSI) as an indicator of soil moisture. Physics and Chemistry of the Earth, Parts $A / B / C$, 30(1-3), 223-230.

Mohammed, S., Alsafadi, K., Mohammad, S., \& Mousavi, N. (2019). Drought trends in Syria from 1900 to 2015. In Proceedings of the 4th international congress of developing agriculture, natural resources, environment and tourism of Iran, Tabriz Islamic Art University In cooperation with Shiraz University and Yasouj University, Tabriz, Iran, 14 August 2019.

Nalbantis, I., \& Tsakiris, G. (2009). Assessment of hydrological drought revisited. Water Resources Management, 23(5), 881-897.

Narasimhan, B., \& Srinivasan, R. (2005). Development and evaluation of Soil Moisture Deficit Index (SMDI) and Evapotranspiration Deficit Index (ETDI) for agricultural drought monitoring. Agricultural and Forest Meteorology, 133(1-4), 69-88.

Novick, K. A., Ficklin, D. L., Stoy, P. C., Williams, C. A., Bohrer, G., Oishi, A. C., et al. (2016). The increasing importance of atmospheric demand for ecosystem water and carbon fluxes. Nature Climate Change, 6(11), 1023.

Önöz, B., \& Bayazit, M. (2003). The power of statistical tests for trend detection. Turkish Journal of Engineering and Environmental Sciences, 27(4), 247-251.

Pálfai, I., \& Herceg, Á. (2011). Droughtness of Hungary and Balkan peninsula. Riscuri si Catastrofe, 9(2), 145-154.

Palmer, W. C. (1965). Meteorological drought, Research paper no. 45 (p. 58). Washington, DC: US Weather Bureau.

Paltineanu, C. R., Mihailescu, I. F., Prefac, Z., Dragota, C., Vasenciuc, F., \& Claudia, N. (2009). Combining the standardized precipitation index and climatic water deficit in characterizing droughts: A case study in Romania. Theoretical and Applied Climatology, 97(3-4), 219.

Pandey, R. P., Pandey, A., Galkate, R. V., Byun, H. R., \& Mal, B. C. (2010). Integrating hydro-meteorological and physiographic factors for assessment of vulnerability to drought. Water Resources Management, 24(15), 4199-4217.

Pongrácz, R., Bartholy, J., \& Kis, A. (2014). Estimation of future precipitation conditions for Hungary with special focus on dry periods. Idójárás, 118(4), 305-321.

Puskás, I., Gál, N., \& Farsang, A. (2012). Impact of weather extremities (excess water, drought) caused by climate change on soils in Hungarian Great Plain (SE Hungary). In J. Rakonczai, Z. S. Ladányi, et al. (Eds.), Review of climate change research program at the university of Szeged (2010-2012) (pp. 73-84). Szeged: Institute of Geography and Geology.

Raziei, T., Martins, D. S., Bordi, I., Santos, J. F., Portela, M. M., Pereira, L. S., et al. (2015). SPI modes of drought spatial and temporal variability in Portugal: Comparing observations, PT02 and GPCC gridded datasets. Water Resources Management, 29(2), 487-504.

Raziei, T., Saghafian, B., Paulo, A. A., Pereira, L. S., \& Bordi, I. (2009). Spatial patterns and temporal variability of drought in western Iran. Water Resources Management, 23(3), 439.

Rencher, A. C. (1998). Multivariate statistical inference and applications (Vol. 338, p. 559). New York: Wiley.

Sábitz, J., Pongrácz, R., \& Bartholy, J. (2014). Estimated changes of drought tendency in the Carpathian Basin. Hungarian Geographical Bulletin, 63(4), 365-378.

Sen, P. K. (1968). Estimates of the regression coefficient based on Kendall's tau. Journal of the American Statistical Association, 63(324), 1379-1389. 
Sohrabi, M. M., Ryu, J. H., Abatzoglou, J., \& Tracy, J. (2015). Development of soil moisture drought index to characterize droughts. Journal of Hydrologic Engineering, 20(11), 04015025.

Spinoni, J., Antofie, T., Barbosa, P., Bihari, Z., Lakatos, M., Szalai, S., et al. (2013). An overview of drought events in the Carpathian Region in 1961-2010. Advances in Science and Research, 10(1), 21-32.

Spinoni, J., Szalai, S., Szentimrey, T., Lakatos, M., Bihari, Z., Nagy, A., et al. (2015). Climate of the Carpathian Region in the period 1961-2010: Climatologies and trends of 10 variables. International Journal of Climatology, 35(7), 1322-1341.

Szabó, S., Elemér, L., Kovács, Z., Püspöki, Z., Kertész, Á., Singh, S. K., et al. (2018). NDVI dynamics as reflected in climatic variables: Spatial and temporal trends-a case study of Hungary. GIScience and Remote Sensing, 20, 1-21.

Szabó, S., Szopos, N. M., Bertalan-Balázs, B., László, E., Milošević, D. D., Conoscenti, C., et al. (2019). Geospatial analysis of drought tendencies in the Carpathians as reflected in a 50-year time series. Hungarian Geographical Bulletin, 68(3), 269-282.

Szalai, S., Auer, I., Hiebl, J., Milkovich, J., Radim, T., Stepanek, P., \& Limanowka, D. (2013). Climate of the greater carpathian region. Final Technical Report. http://www.carpatclim-eu.org.

Szalai, S., Szinell, C. S., \& Zoboki, J. (2000). Drought monitoring in Hungary. Early Warning Systems for Drought Preparedness and Drought Management, 57, 182-199.

Szalai, S., \& Vogt, J. (2011). CARPATCLIM-high resolution gridded database of the Carpathian Region and calculation of drought indices as a contribution to the European Drought Observatory. In WRCP conference (pp. 24-28).

Szinell, C. S., Bussay, A., \& Szentimrey, T. (1998). Drought tendencies in Hungary. International Journal of Climatology: A Journal of the Royal Meteorological Society, 18(13), 1479-1491.

Tan, C., Yang, J., \& Li, M. (2015). Temporal-spatial variation of drought indicated by SPI and SPEI in Ningxia Hui Autonomous region, China. Atmosphere, 6(10), 1399-1421.

Thiel, H. (1950). A rank-invariant method of linear and polynomial regression analysis, Part 3. In Proceedings of Koninalijke Nederlandse Akademie van Weinenschatpen A (Vol. 53, pp. 1397-1412).

Thornthwaite, C. W. (1948). An approach toward a rational classification of climate. Geographical Review, 38(1), 55-94.

Tian, L., \& Quiring, S. M. (2019). Spatial and temporal patterns of drought in Oklahoma (1901-2014). International Journal of Climatology, 39(7), 3365-3378.

Vicente-Serrano, S. M., Beguería, S., \& López-Moreno, J. I. (2010). A multiscalar drought index sensitive to global warming:
The standardized precipitation evapotranspiration index. Journal of Climate, 23(7), 1696-1718.

Vicente-Serrano, S. M., Lopez-Moreno, J. I., Beguería, S., Lorenzo-Lacruz, J., Sanchez-Lorenzo, A., García-Ruiz, J. M., et al. (2014). Evidence of increasing drought severity caused by temperature rise in southern Europe. Environmental Research Letters, 9(4), 044001.

Vido, J., Nalevanková, P., Valach, J., Šustek, Z., \& Tadesse, T. (2019). Drought analyses of the Horné Požitavie Region (Slovakia) in the period 1966-2013. Advances in Meteorology, 2019, 20.

Wang, Q., Wu, J., Lei, T., He, B., Wu, Z., Liu, M., et al. (2014). Temporal-spatial characteristics of severe drought events and their impact on agriculture on a global scale. Quaternary International, 349, 10-21.

Wang, Y., Zhang, J., Guo, E., Dong, Z., \& Quan, L. (2016). Estimation of variability characteristics of regional drought during 1964-2013 in Horqin Sandy Land, China. Water, 8(11), 543.

Wang, W., Zhu, Y., Xu, R., \& Liu, J. (2015). Drought severity change in China during 1961-2012 indicated by SPI and SPEI. Natural Hazards, 75(3), 2437-2451.

Wilhite, D. A. (2000). Drought as a natural hazard: Concepts and definitions. In D. A. Wilhite (Ed.), Drought: A global assessment (pp. 3-18). London: Routledge.

Williams, A. P., Allen, C. D., Macalady, A. K., Griffin, D., Woodhouse, C. A., Meko, D. M., et al. (2013). Temperature as a potent driver of regional forest drought stress and tree mortality. Nature climate change, 3(3), 292.

Xie, H., Ringler, C., Zhu, T., \& Waqas, A. (2013). Droughts in Pakistan: A spatiotemporal variability analysis using the Standardized Precipitation Index. Water International, 38(5), 620-631.

Yue, S., \& Wang, C. Y. (2002). Applicability of prewhitening to eliminate the influence of serial correlation on the Mann-Kendall test. Water Resources Research, 38(6), 4-1.

Zargar, A., Sadiq, R., Naser, B., \& Khan, F. I. (2011). A review of drought indices. Environmental Reviews, 19, 333-349.

Zhang, A., Jia, G., \& Wang, H. (2019). Improving meteorological drought monitoring capability over tropical and subtropical water-limited ecosystems: Evaluation and ensemble of the Microwave Integrated Drought Index. Environmental Research Letters, 14(4), 044025.

Zhang, Q., Sun, P., Li, J., Xiao, M., \& Singh, V. P. (2015). Assessment of drought vulnerability of the Tarim River basin, Xinjiang, China. Theoretical and applied climatology, 121(1-2), 337-347. 